\title{
Digital Divide in the Population of Serbia
}

\author{
Ninoslava Savić \\ Higher School of Professional \\ Business Studies \\ Novi Sad, Serbia
}

ninoslavasavic@gmail.com

\author{
Zoran Radojičić \\ Faculty of Organizational \\ Sciences, \\ Belgrade, Serbia
}

zoran@fon.rs

\begin{abstract}
This paper considers a new kind of social polarization, which comes together with the global process of growing ICTs and transition towards information society. This phenomenon, known as digital divide, equally affects different entities like populations, regions, countries or companies. Monitoring and measuring digital divide becomes the common goal, also implementing the results in new strategies for minimizing them. After giving some recommendations for overcoming digital divide in one country, the model for measuring five types of digital divide and the total digital divide in the domain of population is proposed. The model is applied on the population of Serbia, calculating five sub-indices and the compound digital polarization index for the years 2009 and 2010. Conclusions suggested that the process of minimizing digital divide in Serbia is on, although still very slowly.
\end{abstract}

Keywords: social polarization, information society, digital divide, measuring digital divide, digital polarization index

\section{Introduction}

Corresponding to the process of globalization, the so-called information capitalism is also developed, initiating new forms of social divide and class polarizations (Castells, 1996). This type of divide is nowadays called digital divide. This complex term implies different types of polarizations. On one side, that is polarization between highly developed, usually wealthy countries and regions that are connected to a global computer network and poorly developed and very often poor parts of the world, that are due to their elementary problems still far away from that kind of connection. That is also a kind of polarization, which is monitored within a given society on different levels: between highly educated elite and low educated parts of population, gender polarization, polarization of the young regarding to the older population, as well as the polarization of the rich at one side and the poor at the other. These polarizations are monitored and analyzed by setting and comparing the level of ICT accessibility, the level of ICT use, the level of ICT literacy

Material published as part of this publication, either on-line or in print, is copyrighted by the Informing Science Institute. Permission to make digital or paper copy of part or all of these works for personal or classroom use is granted without fee provided that the copies are not made or distributed for profit or commercial advantage AND that copies 1) bear this notice in full and 2) give the full citation on the first page. It is permissible to abstract these works so long as credit is given. To copy in all other cases or to republish or to post on a server or to redistribute to lists requires specific permission and payment of a fee. Contact Publisher@InformingScience.org to request redistribution permission. etc. in different social groups or in different countries and regions.

Studying and measuring of digital divide between countries and regions is significant from the aspect of discovering the capacity of one nation to participate in the global information society. When digital divide is monitored within one country, it is possible to affect the design and the change of the current de- 
veloping strategies, by measuring the gap between different socio-economic groups in the context of their potentials to participate in ICT application.

The precise indicators and appropriate measures of this complex social phenomenon enable quantitative expression of its movement in time or space. Using them, the preconditions for its regular monitoring and affecting its further course are provided.

The paper offers suggestion of one methodology, by which the social polarization on population, induced by different opportunities of social groups to participate in transition towards information society, is quantitatively expressed.

\section{Digital Divide: The Meaning, Types, and Measurement}

The term digital divide denotes the gap between individuals, households, enterprises or geographical regions that are on different levels of socio-economic development, which is monitored through their possibilities for the access to ICT, as well as their use of Internet in private, social and business activities (OECD, 2001).

The achievement of "information society for all" presents one of political priorities of the European Union, which is emphasized in the European Union project, with the same name (European Commission, 2000, 2002). This political priority determines setting clear goal of minimizing all forms of digital divide. As opposed to digital divide, the terms participation and inclusion are introduced. In the working documents of European Union bodies these terms are used when defining goals such as designing rightful society, with such socio-economic environment in which all citizens, or at least the majority, will be able to enjoy the advantages of information society (European Commission, 2001).

Digital divide presents a complex, multidimensional social phenomenon that is noticed at different levels of monitoring and that causes many consequences on society (Economic and Social Commission for Western Asia, 2005). Its effect is seen in international context, when it is monitored and measured among different countries, as well as in national framework, within a particular country. It is noticed through differences concerning availability of ICT infrastructure, ways of its use and possibility of enjoying the advantages that ICT use provides. Digital divide usually refers to population domain. However, it is also possible to measure and express digital divide among business entities, applying the appropriately defined criteria and measuring models.

Digital divide can be monitored in relation to the environment of a certain country (external digital divide) or it can be confined to one specific country (internal digital divide).

External digital divide refers to differences in possibilities for ICT application and differences in the ways of its application, that can be noticed when a specific country is compared to its environment - other countries, regions, communities of states or geographical units.

Internal digital divide can be monitored on population and on business entities (enterprises).

Internal digital divide of population is studied on different social groups that are classified according to the chosen criteria such as gender, education level, income level, age etc.

Internal digital divide of business entities is studied on different groups of enterprises, classified according to the appropriately chosen relevant criteria (the size of enterprise, field of work, realized profit etc.).

This paper focuses on the digital divide in the domain of population. Concerning digital divide within the population, there are many projects, studies and scientific papers on the international level covering the topic of defining the measuring methodology and expression of the levels of 
digital divide, their comparison to environment and their ranking (Barzilai-Nahon, 2006; ChinChang \& Shu-Fen, 2006; Cuervo \& Menendez, 2006; Selhofer \& Hüsing, 2002; Stiakakis, Kariotellis \& Vlachopoulou, 2009). It is noticed that there is no unique accepted methodology. All methodologies mainly create different social divide according to different criteria chosen to be relevant for digital divide analysis (for example according to gender, education level, income level etc.). In every divide, a certain number of social groups are monitored, that are classified according to the values of criteria being measured. Very often a social group, anticipated to be endangered from the aspect of digital divide, stands out in the case of each individual divide (for example, women, the oldest part of population, part of population with the lowest income level, etc). Finally, various transformations of measured values for chosen indicators formulate one or more compound indices of digital divide levels.

One of the published models for the calculation of digital divide index, developed in the scope of international project Empirica (Selhofer \& Hüsing, 2002) starts from noticing critical groups within the population divided according to different criteria (for example women, older population, low educated population etc.). Taking into account the values of chosen indicators on these critical groups, their average value is calculated as composite index of digital divide.

\section{Overcoming Digital Divide}

Many countries in the world today are faced with serious problems such as poverty, the lack of basic living needs, illiteracy, low rate of school enrollment, high rate of children mortality etc. All these problems are included in the United Nations plan, called Millennium Development Goals (United Nations General Assembly, 2000). It expresses the readiness of the countries members of the United Nations to solve these problems until 2015, with the special accent on the urgency of development and improvement of key economic sectors.

That is why it sounds inappropriately to appeal for ICT investments and construction of modern information society in poorly developed countries faced with serious existential problems. Still, the experience of many developing countries shows that ICT application, as well as application of new technologies in general, have a positive role in stimulation of economic and social development, especially when they are supported by rightful state policy and well balanced development strategy.

Carrying out of adequate measuring, by which the actual state of information society is determined as well as the level of changes in relation to a period of time or in relation to environment are considered to be not avoidable precondition in the fight against digital divide. The results of such measuring serve for designing and correcting strategies which goal is to minimize digital divide. Successful implementation of these strategies enables less developed countries to include into global information society (ESCWA, 2005).

Investments in ICT infrastructure are necessary but not enough condition for construction and progress of an information society. Apart from strengthening of ICT infrastructure, it is necessary to have a parallel investment in strengthening of human resources that will be able to actively support the transition to information society having enough education in the field of ICT.

Effective use of ICT for stimulating of critical sector development, for instance, in education, health and public administration, presents useful means for development of these sectors as well as for quick and secure return of the invested means. At the same time, it is needed to have systematic monitoring and evaluating of ICT use in these sectors in order to enable correction of actual and design of further policy of these investments (Figure 1). 


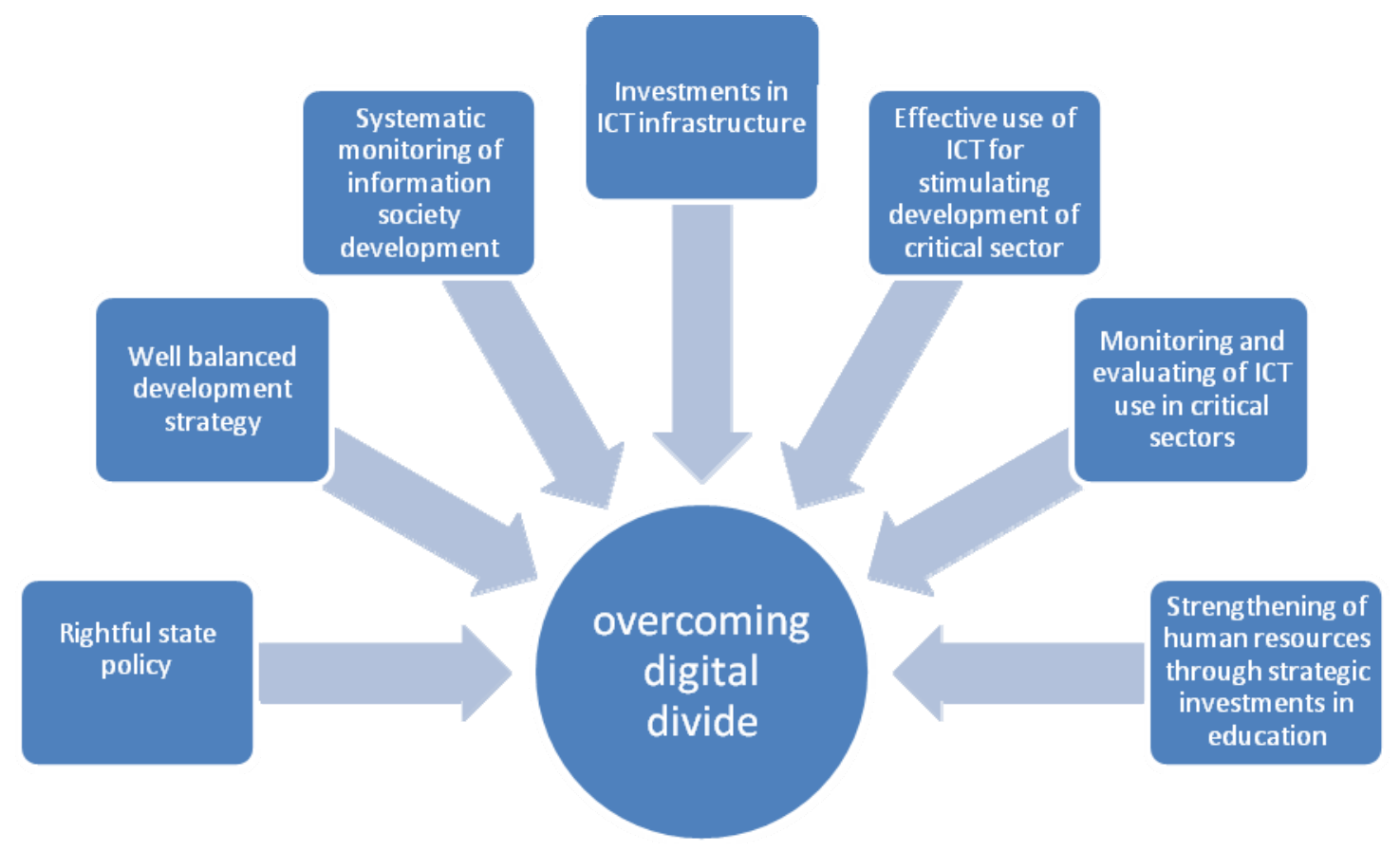

Figure 1: Instruments for overcoming digital divide

It is important to emphasize the key role of human potentials that are capable of carrying out the entire process of transition towards information society. Successful transition implies constant strengthening of human resources through strategic investment in their education that will create conditions for more mass and more effective participation in social, economic, technological and political changes as a result of information era - the so-called e-participation. Therefore, it is necessary to constantly encourage developing countries to carry out the following activities (Figure 2):

- Implementation of institutional and social reforms that support e-participation of citizens,

- Strengthening of information literacy, information culture and critical thinking,

- Promotion and development of life-long learning process in the framework of education process.

Education of people for use of ICT is considered to be the precondition of an information society development. Thus, the information society indicators set, aiming to cover all aspects of its development, must contain, apart from set of indicators of ICT infrastructure and technological readiness of a society, even the set of indicators for measuring ICT readiness of population. 
Strategic

investment in

education

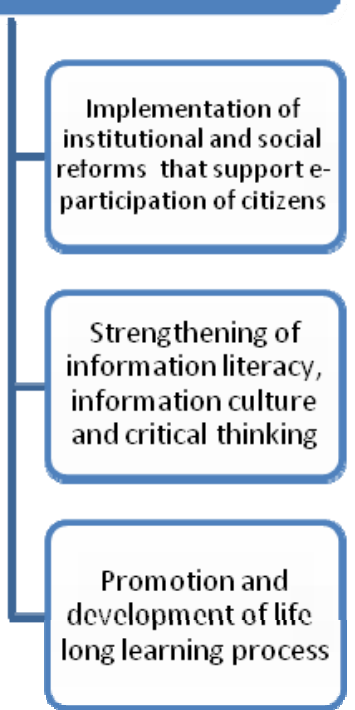

Figure 2: Strategic investment in education

\section{The Aim of Research}

This paper studies whether there are, how great are and in what direction internal digital divide in Serbia within the domain of population are moving. The model that is developed for that purpose is limited by the accessibility of the data at this moment in Serbia. Hence, the results of this research are only the first step in covering this complex issue.

Differences in the level of ICT access and use by households in Serbia, which are consequences of differences in gender, age, income level, education level and development level of the territory of living are noticed. The aim of the research is quantitative expression of total digital divide level on the population in Serbia as well as the level of individual digital divide referring to a particular population divide made on the basis of possible assessed reasons for digital divide. That enables us to monitor the movement of total digital divide on population in Serbia, and to notice the reasons and locate the greatest polarizations caused by the expansion of new technology use.

\section{Research Methodology}

The raw data used as the initial basis for our calculation of digital divide level in Serbia originate from the survey on the usage of ICT in Serbia, carried by the Statistical Office of the Republic of Serbia for years 2009 and 2010. In this survey the methodology of Eurostat was applied (Eurostat, 2007), referring to households and individuals. It was carried out on the territory of the Republic of Serbia (without Kosovo and Metohia). The reference period was within three months before telephone interviews. The survey was carried out on the two-stage stratified sample according to urban criterion. The sample was allocated on the following regions: central Serbia (without Belgrade), Vojvodina and Belgrade, proportional to households' numbers. The scope of the representative sample was 2400 households and 2400 individuals. According to the methodology of Eurostat, the households with at least one member (aged between 16 and 74) and individuals with the same age were covered. The same sample used for households has been applied 
for individuals. The response rate was $96.6 \%$ (2 318 households and 2318 individuals) for the year 2009 and 95.8\% (2 299 households and 2299 individuals) for the year 2010.The research was carried out by phone, including also indirect survey (giving answers instead of the absent person).

\section{Model for Measuring Digital Divide in the Domain of Population}

Our model is based on the classification of total digital divide in the domain of population in relation to the causes of possible polarizations. The following types of digital divide will be considered:

- Digital divide caused by differences in territory development

- Digital divide caused by differences in income level

- Digital divide according to gender

- Digital divide caused by differences in education level

- Digital divide caused by age differences

These five digital divide will be analyzed for the following social groups (Figure 3):
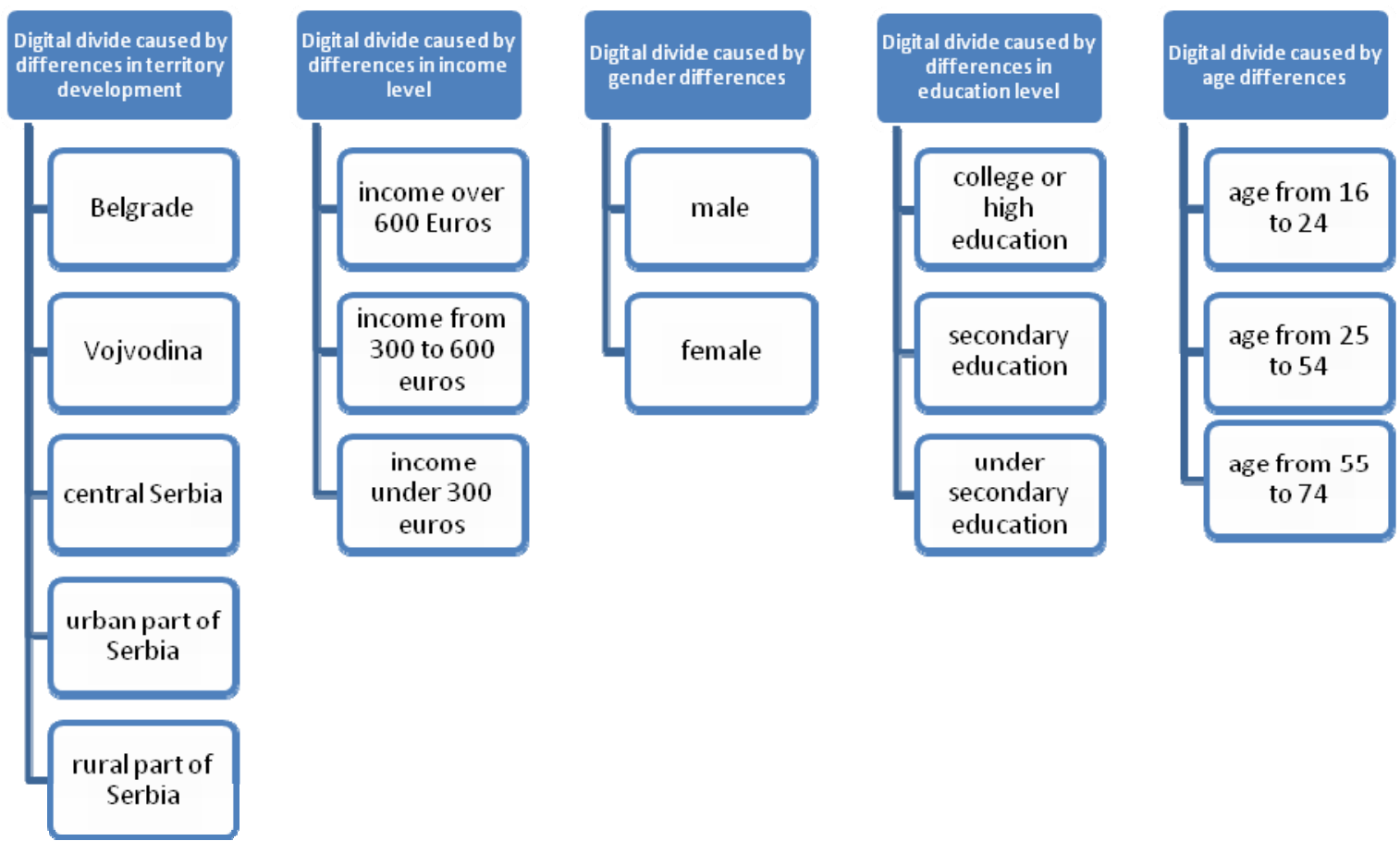

Figure 3: Social groups according to the types of digital divide

For the measuring of digital divide, the following indicators were chosen according to their semantic, taking into account the actual data availability (Figure 4):

- access to computer at home,

- access to Internet at home and

- broadband connection at home - 
for measuring of digital divide caused by differences in income level and digital divide caused by territory development.

- use of computer and

- use of Internet -

for measuring of digital divide caused by gender differences, digital divide caused by differences in education level and digital divide caused by age differences.

This model for the calculation of index and sub-index of digital polarization starts from the idea that measuring of digital polarization in the domain of population means introduction_of the polarization measure within the population divided according to the chosen criterion into groups. In this case, as a measure for the degree of this polarization we take the difference between maximum and minimum values of particular indicator in groups that are classified according to criteria determined by the sub-index. This difference in general varies between zero (when there is no polarization) and the maximum measured value of indicator (which means also the maximal polarization). Dividing this difference with the maximum value of the appropriate indicator, we obtain the value in the range of $[0,1]$.

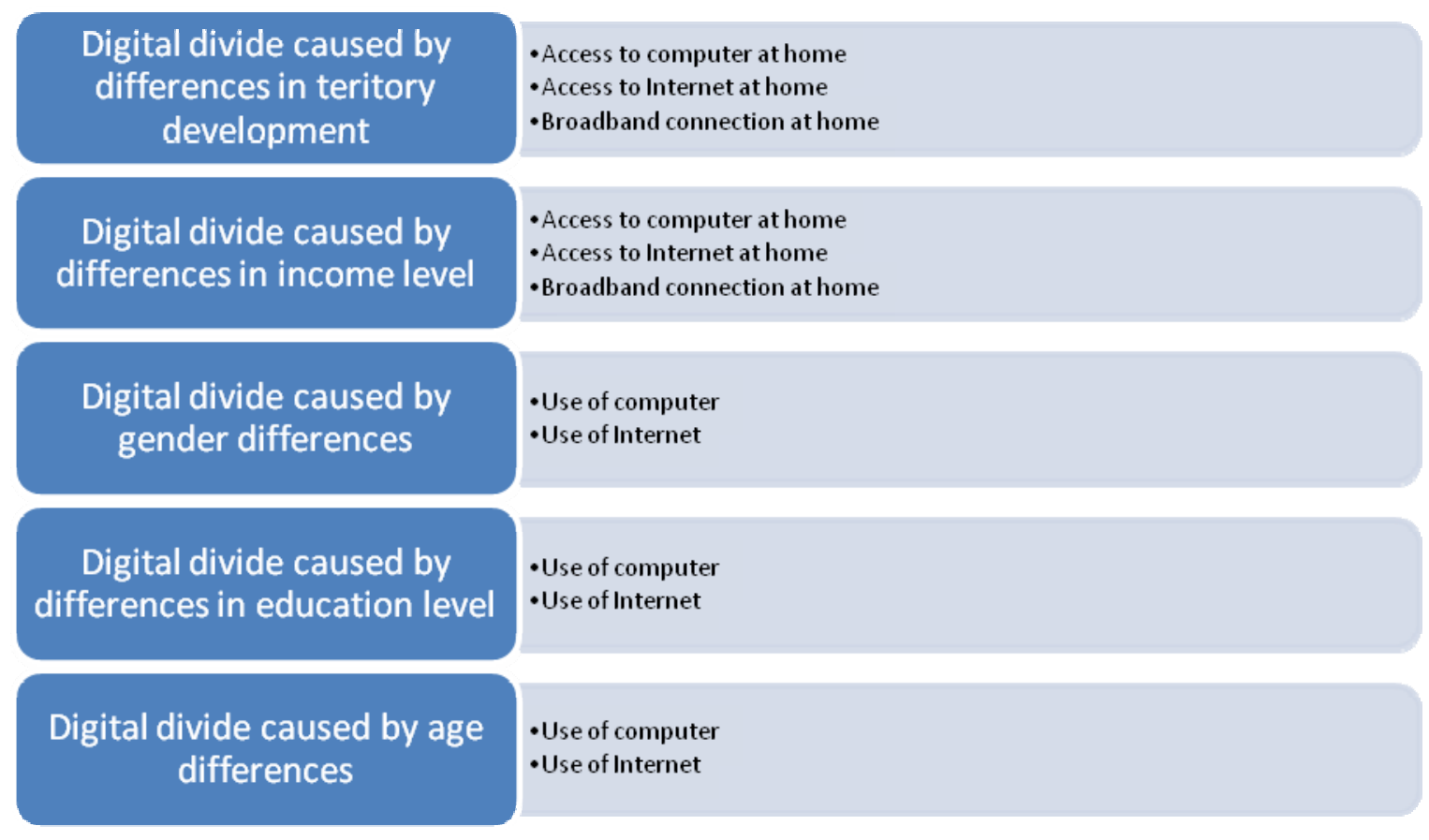

Figure 4: Choice of indicators in sub- indices

The final value of sub-index is obtained as an arithmetic mean of the quotients calculated for all chosen indicators. All indicators have the same weight in this calculation, due to simplicity. The final index of digital polarization is an arithmetic mean of five sub-indices obtained in this way, again with the same weight. (It is also possible to assign different weights to-sub indices in the model, according to assessment of their significance for measuring of total digital polarization.)

If digital polarization index is labeled as DPI and sub-indices of digital polarization as DPIi, $\mathrm{i}=1,5$ then the formula for DPI calculation is as follows: 


$$
D P I=\frac{\sum_{[-1}^{B} D F I t}{5},
$$

where the sub-indices DPIi are calculated according to the formula

$$
D P I i=\frac{\Sigma_{f H_{1}} \frac{X / m a x}{X / \max }}{K t}, \quad i=1,5
$$

where

$$
\begin{aligned}
& \mathrm{Ki}-\text { total number of chosen indicators for sub index DPIi } \\
& \text { Xjmax - maximum measured value of indicator } \mathrm{Xj} \\
& \text { Xjmin - minimum measured value of indicator } \mathrm{Xj}
\end{aligned}
$$

The model for calculating of digital polarization index and digital polarization sub-indices is a flexible and opened system in its nature. That implies that its basic semantics does not change when the set of sub indices, the set of indicators for its quantitative expression and/or the set of defined groups within a specific digital divide are broadened or changed. It is possible to introduce new noticed type of digital divide and to calculate new appropriate sub-indices for them. Measuring of digital polarization sub-indices can also be performed with an expanded list of chosen indicators. Finally, it is possible to introduce a new, different kind of population divide according to the chosen criterion giving new kind of social groups. At the same time, all calculations are performed according to the same defined rules of the model.

It is clear that, the more broadened our model is, the more detailed and precise picture of the digital polarization at the observed population is obtained. This procedure is always restricted by data availability needed for the research, i.e. by the real possibilities to reach the set of necessary data by carrying out such an extensive measuring. Developing countries are, in that sense, in a more difficult situation than developed countries, which regularly conduct different kind of statistical researches.

\section{The Results of Research}

Because of limited space, there are only the examples of the input data shown in Figure 5 and Figure 6 . These are the values of indicators use of computer and use of Internet according to gender (Figure 5) and the values of indicators access to computer at home and access to Internet at home by the income level (Figure 6). All values of indicators expressed the percentages of the population of Serbia with certain measured characteristic.

Table 1 shows the main steps of the calculation of sub-indices and the total digital polarization index according to formulas (1) and (2).

For example, for analyzing digital divide in Serbia in year 2009 caused by gender differences and expressing them quantitatively, we can use our model for computing one sub-index (DPI3) starting from the input data shown in Figure 5. Two indicators for computing DPI3 according to Figure 4 are use of computer and use of Internet.

The maximum value of use of computer is 54,2, while the minimum value of this indicator is 44,6 . For second indicator (use of Internet) maximum value is 42,3 , while the minimum is 34,1 . Computing the values of the mathematical expressions $(54,2-44,6) / 54,2$ and $(42,3-34,1) / 42,3$ 
we get as the result numbers 0,177 and 0,194 . According to (2), the average value of these two numbers is 0,185 and means the final calculated value for sub-index DPI3 for year 2009.

Analogically we compute the remaining four sub-indices. The compound index DPI is the average value for five sub-indices, $0,597,0,763,0,185,0,708$ and 0,875 , according to (1). For the year 2009 this value is 0,626 .

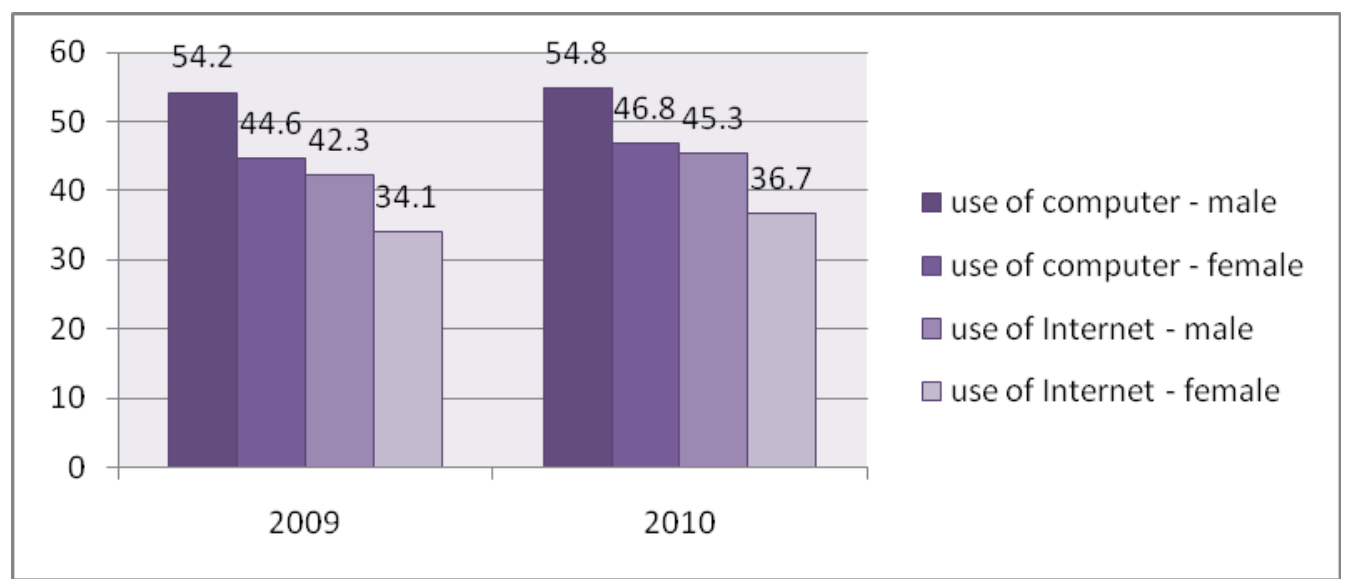

Figure 5: Values of indicators use of computer and use of Internet according to gender

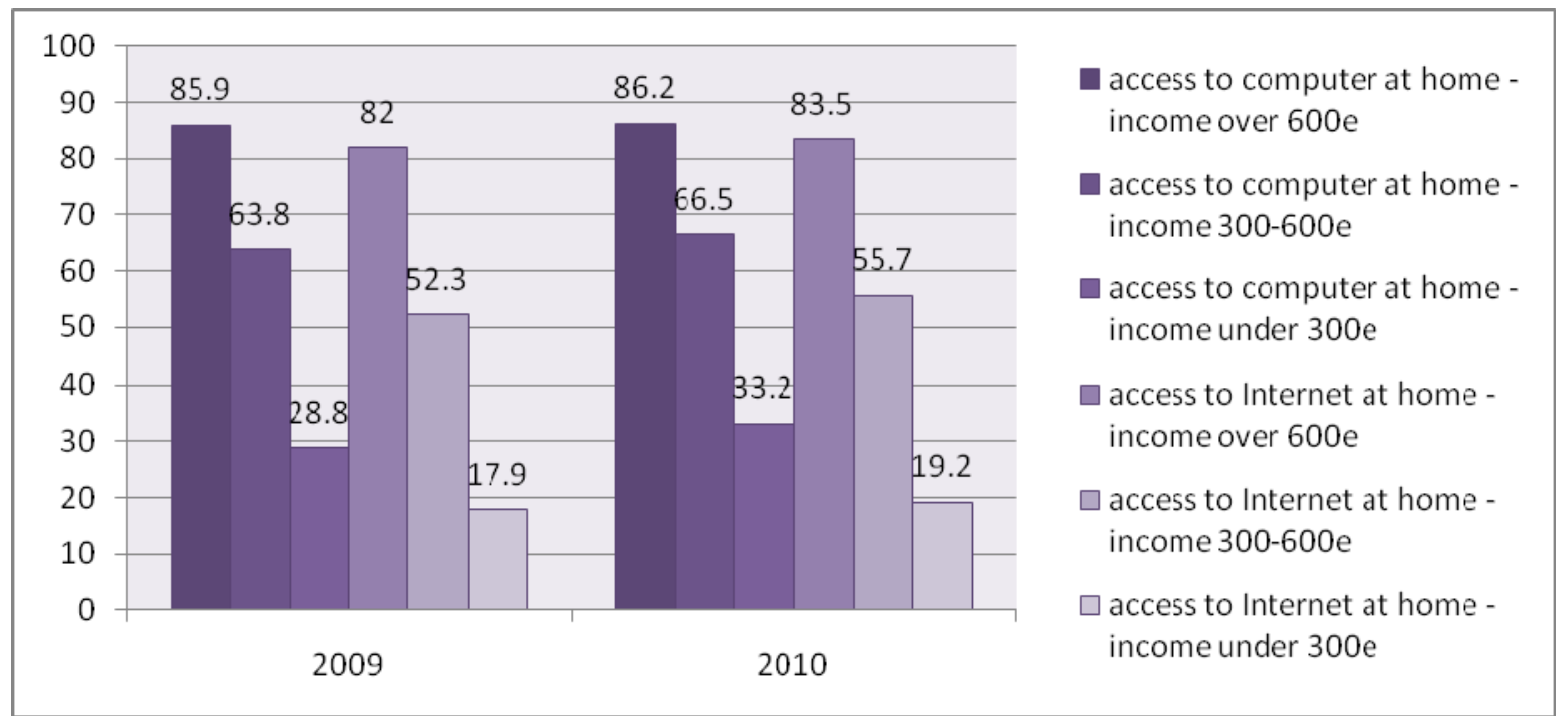

Figure 6: Values of indicators access to computer at home and access to Internet at home by the income level 
Table 1: Calculation of sub-indices and total digital polarization index

\begin{tabular}{|c|c|c|}
\hline VALUES OF INDICATORS AND INDICES & 2009 & 2010 \\
\hline $\begin{array}{l}\text { for DPI1 -according to territory } \\
\text { access to computer - Imax } \\
\text { access to computer - Imin } \\
\text { Imax-Imin/Imax } \\
\text { access to Internet - Imax } \\
\text { access to Internet - Imin } \\
\text { Imax-Imin/Imax } \\
\text { broadband connection - Imax } \\
\text { broadband connection - Imin } \\
\text { Imax-Imin/Imax }\end{array}$ & $\begin{array}{r}59,8 \\
33,6 \\
\mathbf{0 , 4 4} \\
48,6 \\
22 \\
\mathbf{0 , 5 4 7} \\
37,6 \\
7,4 \\
\mathbf{0 , 8 0 3} \\
\end{array}$ & $\begin{array}{r}60,1 \\
38,3 \\
\mathbf{0 , 3 6 2} \\
51,3 \\
24,1 \\
\mathbf{0 , 5 3} \\
41,6 \\
11,4 \\
\mathbf{0 , 7 2 6} \\
\end{array}$ \\
\hline DPI1 & 0,597 & 0,539 \\
\hline $\begin{array}{l}\text { for DPI2 - according to income level } \\
\text { access to computer - Imax } \\
\text { access to computer - Imin } \\
\text { Imax-Imin/Imax } \\
\text { access to Internet - Imax } \\
\text { access to Internet - Imin } \\
\text { Imax-Imin/Imax } \\
\text { broadband connection - Imax } \\
\text { broadband connection - Imin } \\
\text { Imax-Imin/Imax }\end{array}$ & $\begin{array}{r}85,9 \\
28,8 \\
\mathbf{0 , 6 6 5} \\
82 \\
17,9 \\
\mathbf{0 , 7 8 1} \\
58,3 \\
9,1 \\
\mathbf{0 , 8 4 4} \\
\end{array}$ & $\begin{array}{r}86,2 \\
33,2 \\
\mathbf{0 , 6 1 5} \\
83,5 \\
19,2 \\
\mathbf{0 , 7 7} \\
65,6 \\
12,1 \\
\mathbf{0 , 8 1 5} \\
\end{array}$ \\
\hline DPI2 & 0,763 & 0,733 \\
\hline $\begin{array}{l}\text { for DPI3 - according to gender } \\
\text { use of computer - Imax } \\
\text { use of computer - Imin } \\
\text { Imax-Imin/Imax } \\
\text { use of Internet - Imax } \\
\text { use of Internet - Imin } \\
\text { Imax-Imin/Imax }\end{array}$ & $\begin{array}{r}54,2 \\
44,6 \\
\mathbf{0 , 1 7 7} \\
42,3 \\
34,1 \\
\mathbf{0 , 1 9 4}\end{array}$ & $\begin{array}{r}54,8 \\
46,8 \\
\mathbf{0 , 1 4 6} \\
45,3 \\
36,7 \\
\mathbf{0 , 1 9}\end{array}$ \\
\hline DPI3 & 0,185 & 0,168 \\
\hline $\begin{array}{l}\text { for DPI4 - according to education level } \\
\text { use of computer - Imax } \\
\text { use of computer - Imin } \\
\text { Imax-Imin/Imax } \\
\text { use of Internet - Imax } \\
\text { use of Internet - Imin } \\
\text { Imax-Imin/Imax }\end{array}$ & $\begin{array}{r}77,3 \\
27,6 \\
\mathbf{0 , 6 4 3} \\
72,9 \\
16,5 \\
\mathbf{0 , 7 7 3} \\
\end{array}$ & $\begin{array}{r}77,4 \\
28,9 \\
\mathbf{0 , 6 2 7} \\
73 \\
21,7 \\
\mathbf{0 , 7 0 3} \\
\end{array}$ \\
\hline DPI4 & 0,708 & 0,665 \\
\hline $\begin{array}{l}\text { for DPI5 - according to age } \\
\text { use of computer - Imax } \\
\text { use of computer - Imin } \\
\text { Imax-Imin/Imax } \\
\text { use of Internet - Imax } \\
\text { use of Internet - Imin } \\
\text { Imax-Imin/Imax }\end{array}$ & $\begin{array}{r}85,5 \\
10,6 \\
\mathbf{0 , 8 7 6} \\
63,6 \\
8 \\
\mathbf{0 , 8 7 4}\end{array}$ & $\begin{array}{r}94,4 \\
11,8 \\
\mathbf{0 , 8 7 5} \\
84,4 \\
8,4 \\
\mathbf{0 , 9} \\
\end{array}$ \\
\hline DPI5 & 0,875 & 0,887 \\
\hline DPI & 0,626 & 0,5984 \\
\hline
\end{tabular}




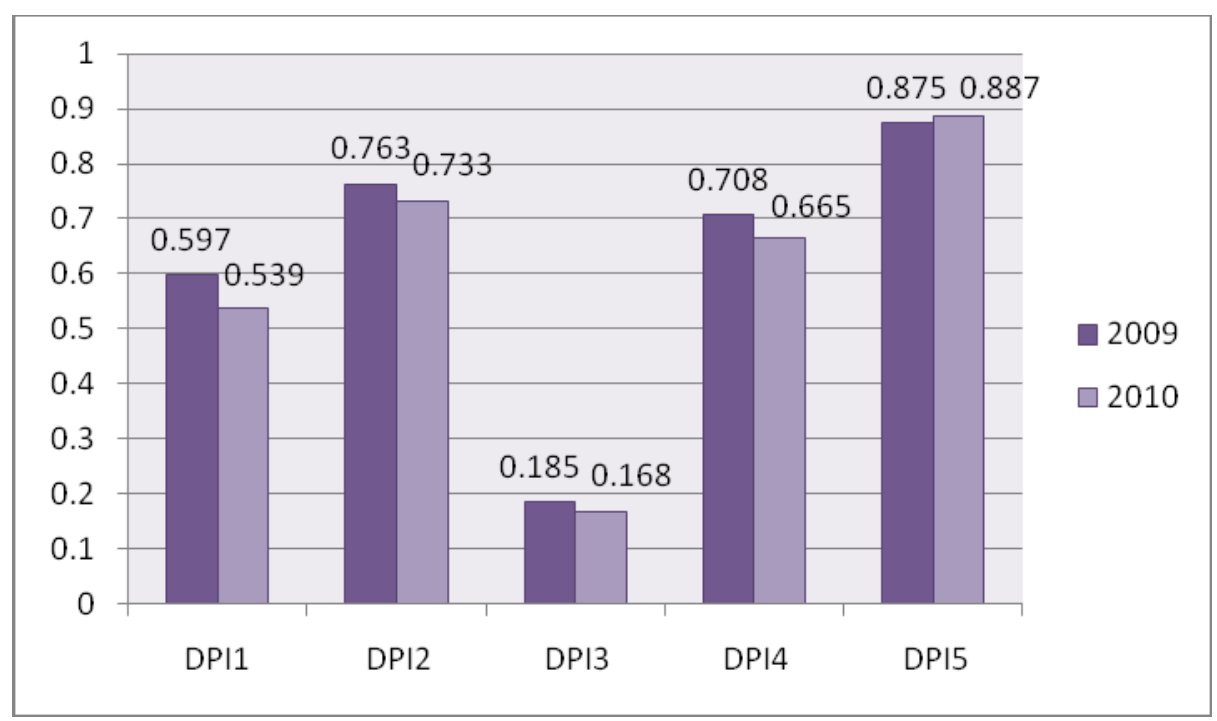

Figure 7: Fluctuation of sub-indices

According to the chart shown in Figure 7, the greatest digital polarization in Serbia refers to those caused by the age differences. It is alarming that this digital divide is the only type of digital divide in Serbia showing the increasing trend (0,875 in 2009, then 0,887 in 2010.). That points to deepening of the gap between the old and the young when ICT use in the population of Serbia is concerned.

The lowest digital polarization index in Serbia, thus the smallest gap, showing even the falling trend, is according to gender differences in ICT access and use.

The remaining three indices are within interval of 0,539 to 0,763 and all of them show falling trend in time, so reducing of the gap between appropriate social groups.

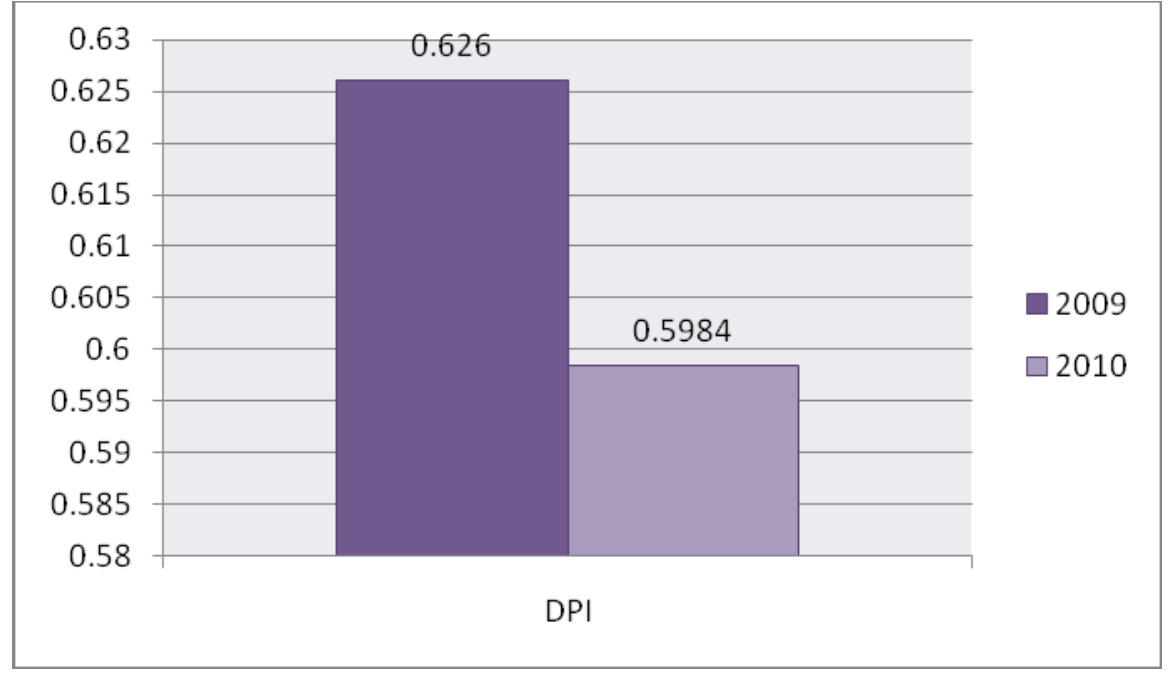

Figure 8: DPI value fluctuation

The total digital polarization index in Serbia is 0,626 for the year 2009 i.e. 0,598 for the year 2010 (Figure 8), showing the falling trend of total gap in the population of Serbia in relation to accessibility and use of ICT. 


\section{Applicability of the Model}

The proposed model, which quantitatively expresses the level of digital divide, provide the opportunity for better monitoring the state of digital polarization within country and its trends by using the compound indices. Although compound indices hide characteristics expressed by single indicators, analyzing only single ICT indicators list could be too difficult for drawing conclusions about this complex phenomenon.

The illustration of this statement is given considering the case of Serbia and its position in the region related to the development of information society. According to Eurostat's data bases (Eurostat, 2010), the ranking of the most of ICT benchmarking indicators shows that the position of Serbia is at the bottom of list for European countries. Serbia is also the last among the countries from the former Yugoslavia. Table 2 shows the values of two random selected ICT indicators for a subset of European countries in the year 2009. Similar case is also with other ICT benchmarks. In spite of regular surveys on the usage of ICT in Serbia, performed each year starting from 2006, we find that the values for some indicators are still marked as N/A (not accessible). From these analytical data, without any transformation, it is difficult to conclude about internal digital divide level and its trends within country. In this fact lie the power and the applicability of our model.

Table 2: Values of two ICT indicators for selected countries in year 2009

\begin{tabular}{|l|c|c|}
\hline \multicolumn{1}{|c|}{ Country } & $\begin{array}{c}\text { \% of individuals } \\
\text { with } \\
\text { Internet access } \\
\text { at home }\end{array}$ & $\begin{array}{c}\text { \% of households } \\
\text { with } \\
\text { Internet access }\end{array}$ \\
\hline Iceland & 89 & 90 \\
\hline Netherlands & 87 & 90 \\
\hline Norway & 87 & 86 \\
\hline Luxemburg & 82 & 87 \\
\hline Denmark & 82 & 63 \\
\hline Belgium & 69 & 65 \\
\hline EU27 & 58 & 64 \\
\hline Slovenia & 54 & 50 \\
\hline Croatia & 42 & 42 \\
\hline $\begin{array}{l}\text { Former Yugoslav } \\
\text { Republic of Macedonia }\end{array}$ & 40 & 48 \\
\hline Portugal & 39 & 37 \\
\hline Serbia & 28 & 38 \\
\hline Romania & & 30 \\
\hline Turkey & 31 & \\
\hline
\end{tabular}

The model is especially significant for the definition of development policy that could help improvement in critical sectors and socially disadvantaged groups, which lead to the achievement of an inclusive information society. Digital Agenda for Europe (European Commission, 2010), among other issues, highlights the process of enhancing digital literacy, skills and inclusion. In this document, European Commission proposes a series of measures and policy actions to promote take-up of digital technologies and improving access by potentially disadvantaged groups, like elderly, less-literate, low-income persons and people with disabilities. E-Inclusion is among 
the priorities of the 2010 policy initiative of the EU. i2010 eGovernment Action Plan (2006) identifies five priority areas, among which is the priority Access for all, which means a global fight against all kinds of digital divide.

\section{Conclusion}

Global process of the expansion of new ICT and appearance of new information era irrepressibly bring changes to the world community, influencing indirectly the speed of development of its members. The appearance of new forms of polarization and social inequalities can be observed on the population, companies, countries and regions. Monitoring of all types of digital divide requires serious approach, periodical measuring and analysis of results. The results of systematic evaluation of this phenomenon in a certain society are especially significant for the designers of development strategies, who are in a position to affect on decreasing social "e-inequalities".

The proposed model for the measuring of total and specific - individual digital polarization is applied to the population of Serbia. The starting point for the calculation of digital polarization index and five sub-indices were the results of the research on the ICT use in Serbia for 2009 and 2010 (Statistical Office of the Republic of Serbia, 2009, 2010). The case of Serbia showed that there is a significant digital polarization in the population, but it is, fortunately, slightly falling down. As the results show that the gap between the young and the old is deepened, it is important to pay attention to the population older than 55, which shows the greatest lagging behind in the ICT use.

At the end, this paper aims to reveal are there internal digital divide within population of Serbia, which kind of them are the most concerning and in what direction they are moving thru the time. The scope of this research was limited by the accessibility of the data to only some aspects of the digital divide. However, the model is open to adding new measuring concepts with the same methodology, as it was explained. The causes of digital divide, although very important, were not the subject of this paper and the model. For this kind of extensively research a lot of new benchmarking indicators, which are not accessible at this moment in Serbia, are required.

\section{References}

Barzilai-Nahon, K. (2006). Gaps and bits: Conceptualizing measurements for digital divide/s. The Information Society, 22(5), 269-278.

Castels, M. (1996). The information age: Economy, society and culture:Volume I,The rise of the network society. Blackwell.

Chin-Chang, H. \& Shu-Fen. T. (2006). From digital divide to digital inequality: The global perspective. International Journal of Internet and Enterprise Management, 4(3), 215-227.

Cuervo, M. R. V., \& Menendez, A. J. L. (2006). A multivariate framework for the analysis of the digital divide: Evidence for the European Union-15. Information \& Management, 43, 756-766.

Economic and Social Commission for Western Asia. (2005). Information Society Indicators. UN.

eInclusion. (n.d.). Retrieved December 8, 2010, from http://ec.europa.eu/information_society/activities/einclusion/index_en.htm

European Commission. (2000). eEurope action plan - An information society for all.

European Commission. (2001). e-Inclusion - The information society's potential for social inclusion in Europe. Commission Staff Working Document SEC(2001)1428, with the support of the High Level Group "Employment and Social Dimension of the Information Society" (ESDIS).

European Commission. (2002). e-Europe 2005: An information society for all - Action Plan to be Presented in view of the Seville European Council ref. COM(2002) 263 final. 
European Commission. (2006). i2010 eGovernment action plan - Accelerating eGovernment in Europe for the benefit of all $\operatorname{COM(2006)} 173$ final. Retrieved October 20, 2010, from http://europa.eu/legislation summaries/information society/124226j_en.htm

European Commission. (2010). A digital agenda for Europe. COM/2010/0245 f/2. Retrieved December 8, 2010, from http://ec.europa.eu/information_society/digital-agenda/index_en.htm

Eurostat. (2007). Methodological manual for statistics on the information society, Survey year 2007v2.0. Luxembourg. Retrieved October 21, 2010, from http://europa.eu.int/estatref/info/sdds/en/isoc/isoc metmanual_2007.pdf

Eurostat. (2010). Information society statistics home page. Retrieved December 8, 2010, from http://epp.eurostat.ec.europa.eu/portal/page/portal/information_society/data/database

OECD. (2001). Understanding the digital divide. Paris: OECD Publications.

Statistical Office of the Republic of Serbia. (2009). Usage of information and communication technologies in the Republic of Serbia. Beograd.

Statistical Office of the Republic of Serbia. (2010). Usage of information and communication technologies in the Republic of Serbia. Beograd.

Selhofer, H., \& Hüsing T. (2002). IST 2002: The digital divide index-A measure of social inequalities in the adoption of ICT. Copenhagen.

Stiakakis, E., Kariotellis, P., \& Vlachopoulou, M. (2009). From the digital divide to digital inequality: A secondary research in the European Union. In A. B. Sideridis \& C. Z. Patrikakis (Eds.), Next generation society - Technological and legal issues (pp. 43-55). Springer.

United Nations General Assembly. (2000). United Nations Millennium Declaration.

\section{Biographies}
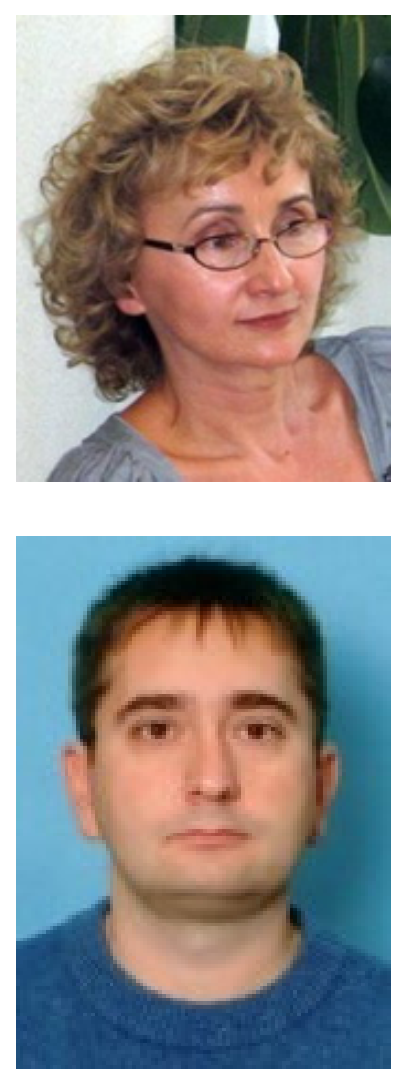

Ninoslava Savić is a Senior Lecturer at Higher School of Professional Business Studies in Novi Sad, Department of Informatics. She holds a B.A. in Mathematics from Novi Sad University and a M.Sc. in Information Systems from University of Belgrade. Her research interests are information society, e-business, information systems and methodologies for measuring e-development.

Zoran Radojičić is an Assistant Professor at Faculty of Organizational Sciences in Belgrade, Department of Operational Research and Statistics. He holds a B.A. in Organizational Sciences, a M.Sc. in Statistics and a Ph.D. in Statistics, all from University of Belgrade. His research interests are computational statistics, applied statistics, biostatistics, information systems, Internet and e-business. 